Vol. 11 No. 012020

e-issn : 2622-0148, p-issn : 2087-0035

\title{
HUBUNGAN PENGETAHUAN IBU HAMIL PRIMIGRAVIDA DENGAN DETEKSI DINI TANDA BAHAYA KEHAMILAN DI PMB BIDAN "N" DI KABUPATEN GOWA
}

Relationship between Primigravida Pregnant Women's Knowledge and Early Detection of Pregnancy Danger Signs at PMB Midwife "N" Gowa Regency

\author{
Nurjaya ${ }^{1}$, Suriani $\mathrm{Bi}^{2}$, Hardianti ${ }^{3}$, Subriah ${ }^{4}$ \\ 1,2,4 Poltekkes Kemenkes Makassar \\ ${ }^{3}$ Alumni D IV Jurusan Kebidanan Poltekkes Makassar Makassar \\ Email: subriaharsjad@gmail.com
}

\begin{abstract}
Early detection aims to identify the danger signs of pregnancy early so that it can be identified or immediately get treatment to reduce maternal and neonatal mortality morbidity and mortality (WHO, 2018). Knowledge of the methods of early detection of pregnancy danger can increase the awareness of pregnant women, especially primigravidas, to be able to detect early detection of pregnancy danger signs to be able to detect any danger signs in pregnancy. Someone also needs motivation, which is positive encouragement both from themselves and others. With the method used through a questionnaire and with a cross-sectional design. The subjects of this study were all primigravida pregnant women who came to have their pregnancies examined at the PMB Midwife "N" in Gowa Regency. The research design uses a Non Probability sampling technique. The statistical analysis used in this study was the chi-square statistic, with a confidence level of $\alpha=0.05$. The results of the study revealed that the significance value of the knowledge by early detection of first trimester pregnancy danger $p=0.015(p<0.05)$ with a coefficient $(P h i=0.365)$, knowledge by early detection of the second trimester pregnancy danger $p=0,000(p<0$, 05) with a coefficient $(P h i=1,000)$, knowledge by early detection of third trimester pregnancy danger $p=0.012(p$ $<0.05)$ with a coefficient value (Phi $=0.548)$. So that it can be concluded that there is a relationship between knowledge and early detection of danger signs of pregnancy. Therefore, educators are expected to increase their role in conveying knowledge about early detection of pregnancy danger signs in an interesting manner to be able to increase their knowledge and skills in applying it.
\end{abstract}

Keywords: Early Detection, Knowledge, Primigravida Pregnant Women, Pregnancy Hazard Signs

\section{ABSTRAK}

Deteksi dini bertujuan untuk mengidentifikasi tanda bahaya kehamilan secara dini sehingga dapat diketahui atau segera mendapatkan pengobatan untuk mengurangi angka morbiditas dan mortalitas angka kematian ibu dan bayi (WHO, 2018). Pengetahuan mengenai metode deteksi dini tanda bahaya kehamilan dapat meningkatkan kesadaran ibu hamil khususnya primigravida agar mampu mendeteksi adanya tanda bahaya pada kehamilan. Selain itu seseorang juga memerlukan motivasi, yaitu dorongan yg positif baik itu berasal dari diri sendiri maupun orang lain. Dengan metode yang digunakan melalui kuesioner dan dengan rancangan cross sectional. Subyek penelitian ini adalah semua ibu hamil primigravida yang datang memeriksakan kehamilannya di PMB Bidan "N" Kabupaten Gowa. Metode Pengambilan sampel dengan teknik Non Probability Sampling. Analisis statistik yang digunakan dalam penelitian ini adalah statistik chi-square, dengan tingkat kepercayaan $a=0,05$. Hasil penelitian diketahui bahwa nilai signifikansi pengetahuan dengan daeteksi dini tanda bahaya kehamilan trimester I $p=0,015$ $(p<0,05)$ dengan nilai koefisien (Phi=0,365), pengetahuan dengan daeteksi dini tanda bahaya kehamilan trimester II $p=0,000(p<0,05)$ dengan nilai koefisien (Phi=1,000), pengetahuan dengan deteksi dini tanda bahaya kehamilan trimester III $p=0,012(p<0,05)$ dengan nilai koefisien (Phi=0,548). Sehingga dapat disimpulkan bahwa ada hubungan antara pengetahuan dengan deteksi dini tanda bahaya kehamilan. Oleh karena itu, diharapkan pendidik meningkatkan perannya dalam menyampaikan pengetahuan tentang deteksi dini tanda bahaya kehamilan secara menarik sehingga mampu meningkatkan pengetahuan dan keterampilan dalam mengaplikasikannya.

Kata kunci : Deteksi Dini, Pengetahuan, Primigravida, Tanda Bahaya Kehamilan

\section{PENDAHULUAN}

Pada umumnya kehamilan berkembang dengan normal dan menghasilkan kelahiran bayi yang sehat cukup bulan melalui jalan lahir, namun terkadang tidak sesuai dengan yang diharapkan. Sulit diketahui sebelumnya bahwa kehamilan akan terjadi masalah. Tanda bahaya kehamilan harus dikenali dan terdeteksi sejak dini sehingga dapat ditangani dengan benar karena setiap tand $\begin{array}{lll}\text { a bahaya } & \text { kehamilan bisa } \\ \text { mengakibatkan komplikasi kehamilan. } & \end{array}$

Berdasarkan penelitian, telah diakui saat ini bahwa setiap kehamilan dapat memiliki potensi dan membawa risiko bagi ibu. WHO memperkirakan sekitar $15 \%$ dari seluruh wanita hamil akan berkembang menjadi komplikasi yang berkaitan 
dengan kehamilannya dan dapat mengancam jiwanya. Bidan sebagai pemberi pelayanan kebidanan akan menemukan wanita hamil dengan komplikasi-komplikasi yang mungkin dapat mengancam jiwa. Oleh karena itu, bidan harus dapat mendeteksi sedini mungkin terhadap tanda-tanda bahaya pada ibu hamil yang mungkin akan terjadi, karena setiap wanita hamil tersebut beresiko mengalami komplikasi. Yang sudah barang tentu juga memerlukan kerjasama dari para ibu-ibu dan keluarganya, yang dimana jika tanda-tanda bahaya ini tidak dilaporkan atau tidak terdeteksi, dapat mengakibatkan kematian ibu.

Pada umumnya 80-90\% kehamilan akan berlangsung normal dan hanya $10-12 \%$ kehamilan yang di sertai dengan penyulit atau berkembang menjadi kehamilan patologis . kehamilan patologis sendiri tdak terjadi secara mendadak karena kehamilan dan efeknya terhadap organ tubuh berlangsung secara bertahap dan berangsur-angsur. (Prawirohardjo, 2016 ;h.281)

Deteksi dini gejala dan tanda bahaya selama kehamilan merupakan upaya terbaik untuk mencegah terjadinya gangguan yang serius terhadap kehamilan ataupun keselamatan ibu hamil. (Prawirohardjo, 2016; h. 281)

Penyebab kematian ibu di dunia adalah setelah kondisi yang ada $28 \%$, hipertensi dalam kehamilan $14 \%$, komplikasi abortus $8 \%$, perdarahan $27 \%$, infeksi $11 \%$, partus lama dan lainnya $9 \%$ dan penggumpalan darah (embolism) 3\% (WHO, 2014). Masalah penurunan Angka Kematian Ibu (AKI) di Indonesia menurut SDKI tahun 2012 menunjukkan peningkatan AKI yang signifikan yaitu menjadi 359 kematian ibu per 100.000 kelahiran hidup. AKI kembali menunjukkan penurunan menjadi 305 kematian ibu per 100.000 kelahiran hidup (Kemenkes RI, 2015).

Provinsi Sulawesi Selatan (Sulsel) masuk 10 besar daftar wilayah provinsi penyumbang angka kematian ibu dan bayi di Indonesia pada tahun 2017.Data ini dirilis langsung Dinas Kesehatan (Dinkes) Sulsel, Jumlah kematian ibu di tahun 2017 lalu mencapai 115 kasus,sedangkan kematian bayi capai 1.059 kasus.

Penyebab kematian ibu di Sulsel disebabkan pendarahan terbanyak dikisaran 40 kasus dan hipertensi kehamilan 35 kasus. Makanya, atas kondisi ini perlu dilakukan deteksi dini pada saat Antenatal Care dan penanganan yang tepat serta sesuai standar sehingga dapat mencegah kedua kondisi tersebut

Persoalan-persoalan tersebut diatas juga terjadi karena ibu hamil terlambat mengenali tanda bahaya, terlambat memutuskan mencari pertolongan melalui fasilitas kesehatan dan terlambat mencapai fasilitas pelayanan kesehatan yang memadai (3 terlambat). Masalah lain yang menyebabkan AKI yakni terlalu muda menikah, terlalu sering hamil, terlalu banyak melahirkan dan terlalu tua saat hamil (4 Terlalu), sehingga memiliki resiko tinggi kematian, karena itu masyarakat perlu mengetahui faktor-faktor tersebut (Sherry, 2015)

Berdasarkan hasil praktek komprehensif yang pernah di lakukan oleh peneliti di PMB Bidan N Kabupaten Gowa pada bulan Juni 2018. Peneliti mendapatkan bahwa masih banyaknya ibu hamil terutama ibu hamil primigravida yang belum mengetahui apa itu deteksi dini tanda bahaya kehamilan, yang kapan saja bisa terjadi pada kehamilannya apabila tidak dilakukan pengawasan pada kehamilan.

Hal tersebut menjadi alasan mengapa penyusun memilih tema tanda-tanda bahaya pada kehamilan dan tertarik untuk membahasnya lebih jauh melalui penelitian. Berdasarkan latar belakang diatas maka penulis membuat rumusan masalah pada penelitian ini yaitu Bagimana hubungan pengetahuan ibu hamil primigravida dengan deteksi dini tanda bahaya kehamilan di PMB Bidan "N" Kabupaten Gowa?

\section{METODE PENELITIAN}

\section{Desain, Tempat, dan Waktu}

Penelitian ini adalah metode deskriptif kuantitatif. Pendekataan waktu yang digunakan secara cross sectional yaitu data yang menunjukan titik waktu tertentu atau pengumpulannya dilakukan dalam waktu yang bersamaan (Riwidikdo,2012)

Pada penelitian ini mendiskripsikan hubungan pengetahuan ibu hamil primigravida dengan deteksi dini tanda bahaya kehamilan.Penelitian dilaksanakan di PMB Bidan N Kabupaten Gowa, dan data diambil pada bulan Maret-Mei 2019

\section{Populasi dan Sampel Penelitian}

Adapun populasi dari penelitian ini adalah seluruh ibu hamil primigravida trimester I II III yang datang untuk memeriksakan kehamilannya di PMB Bidan N Kabupaten Gowa. Jumlah populasi ibu hamil primigravida bulan September-november tahun 2018 adalah 103 orang. Sampel pada penelitian adalah ibu hamil primigravida yang berkunjung untuk memeriksakan kehamilannya di PMB Bidan N Kabupaten Gowa. Pemilihan sampel dilakukan dengan menetapkan subjek yang memenuhi kriteria dalam penelitian.

Penentuan besar sampel dalam penelitian ini sesuai dengan metode No Probability Sampling yaitu Purposive Random Sampling dimana penentuan jumlah minimal yang di jadikan subjek penelitian di sesuaikan dengan kriteria yang di tetapkan dalam penelitian ini dengan jumlah responden sebanyak 50 responden dengan di bagi berdasarkan trimester 
yaitu 13 responden teimester $\mathrm{I}, 16$ responden trimester II, dan 21 responden trimester III.

Instrumen penelitian yang digunakan adalah kuesioner Metode Pengumpulan Data Data Primer dan Data Sekunder berupa data jumlah ibu hamil primigravida yang berkunjung ke PMB Bidan N Kabuoaten Gowa pada bulan September-November 2018.

Analisis data dilakukan dengan menggunakan program SPSS For Windows dan kemudian data disajikan dalam bentuk tabel distribusi disertai dengan penjelasannya. Analisis data dilakukan dengan dua cara, yaitu: Analisis bivariat ini dilakukan untuk mengetahui cross tabulation dengan menggunakan program SPSS (statistical package for social science). Analisis hubungan akan dilakukan menggunakan tabulasi silang dan uji statistik $\mathrm{Chi}$ Square. Analisis ini bertujuan untuk mengetahui kemaknaan hubungan dan kuatnya hubungan dari setiap variabel penelitian

\section{HASIL}

1. Analisis Univariat pada penelitian ini bertujuan untuk melihat frekuensi dan presentase dari variable dependen yaitu deteksi dini tanda bahaya kehamilan serta variable inpeneden yaitu pengetahuan ibu hamil primigaravida

\section{a. Pengetahuan}

Tabel 5.1

Distribusi Frekuensi responden menurut pengetahuan ibu hamil primigravida yang memeriksakan kehamilannya di PMB Bidan "N" Kabupaten Gowa

\begin{tabular}{ccc}
\hline Deteksi dini & $\mathbf{F}$ & $\%$ \\
\hline Tahu & 20 & $95,2 \%$ \\
Tidak Tahu & 1 & $4,8 \%$ \\
\hline Total & 21 & $100 \%$ \\
\hline
\end{tabular}

Sumber : Data Primer, 2019

Berdasarkan table 5.1 menunjukkan tabel distribuasi frekuensi responden menurut pengetahuan ibu hami primigravida yang memeriksakan kehamilannya dari 50 responden diperoleh data bahwa ada 43 responden $(86 \%)$ tahu tentang kehamilan dan 7 responden (14\%) yang tidak tahu tentang pemeriksaan kehamilan b. Deteksi dini tanda bahaya kehamilan menurut responden trimester I.

Tabel 5.2

Distribusi frekuensi Deteksi dini tanda bahaya menurut responden trimester 1 yang memeriksakan kehamilannya di PMB Bidan "N" Kabupaten Gowa

\begin{tabular}{ccc}
\hline Deteksi dini & $\mathbf{F}$ & $\%$ \\
& & \\
\hline Tahu & 12 & $92,3 \%$ \\
Tidak Tahu & 1 & $7,7 \%$ \\
\hline Total & 13 & $100 \%$ \\
\hline
\end{tabular}

Sumber : Data Primer 2019

Berdasarkan tabel 5.2 menunjukkan distribusi frekuensi responden menurut deteksi dini tanda bahaya trimester I dari 13 responden diperoleh data 12 responden (92,3\%) yang tahu mendeteksi dini tanda bahaya pada kehamilan dan 1 responden $(7,7 \%)$ yang tidak tahu mendeteksi secara dini tanda bahaya pada kehamilan.

c. Deteksi dini tanda bahaya menurut responden trimester II

Tabel 5.3

Distribusi frekuensi Deteksi dini tanda bahaya menurut responden trimester II yang memeriksakan kehamilannya di PMB Bidan " $\mathrm{N}$ " Kabupaten Gowa

\begin{tabular}{ccc}
\hline Pengetahuan & $\mathrm{F}$ & $\%$ \\
\hline Tahu & 43 & $86 \%$ \\
Tidak tahu & 7 & $14 \%$ \\
\hline Total & 50 & $100 \%$ \\
\hline
\end{tabular}

Sumber: Data Primer 2019

Berdasarkan tabel 5.3 menunjukkan distribusi frekuensi responden menurut deteksi dini tanda bahaya trimester II dari 16 responden diperoleh data 14 responden $(87,5 \%)$ yang tahu mendeteksi secara dini tanda bahaya pada kehamilan dan 2 responden $(12,5 \%)$ yang tidak tahu mendeteksi secara dini tanda bahaya pada kehamilan. 
d. Deteksi dini tanda bahaya menurut responden trimester II

\section{Tabel 5.4}

Distribusi frekuensi Deteksi dini tanda bahaya menurut responden trimester III yang memeriksakan kehamilannya di PMB Bidan "N" Kabupaten Gowa

\begin{tabular}{ccc}
\hline Deteksi dini & $\mathbf{F}$ & $\%$ \\
\hline Tahu & 14 & $87,5 \%$ \\
Tidak Tahu & 2 & $12,5 \%$ \\
\hline Total & 16 & 100 \\
\hline
\end{tabular}

Sumber: Data Primer 2019

Berdasarkan tabel 5.4 menunjukkan distribusi frekuensi responden menurut deteksi dini tanda bahaya trimester III dari 21 responden diperoleh data 20 responden
$(95,2 \%)$ yang tahu mendeteksi secara dini tanda bahaya pada kehamilan dan 1 responden $(4,8 \%)$ yang tidak tahu mendeteksi secara dini standa bahaya pada kehamilan.

2. Analisis Bivariat

Analisis digunakan untuk mengetahui hubungan antara variable independen dengan variable dependen.

Untuk menilai apakah ada hubungan pengetahuan dan deteksi dini tanda bahaya kehamilan pada ibu hamil primigravida maka digunakan uji statistik Chi-square dengan tingkat kemaknaan $\mathrm{a}=0,05$ atau interval kepercayaan $p<0,05$ menggunakan bantuan program SPSS 21,0for windows.

a. Hubungan antara pengetahuan dengan deteksi dini tanda bahaya trimester I

Tabel 5.5

Hubungan pengetahuan dengan deteksi dini tanda bahaya trimester I di PMB Bidan "N" Kabupaten Gowa

\begin{tabular}{ccccccccc}
\hline Pengetahuan & \multicolumn{3}{c}{$\begin{array}{c}\text { Deteksi dini tanda bahaya } \\
\text { kehamilan trimester I }\end{array}$} & Jumlah & Nilai $\boldsymbol{p}$ & Nilai ph(i) \\
& $\mathrm{N}$ & $\%$ & $\mathrm{~N}$ & $\%$ & $\mathrm{n}$ & $\%$ & & \\
\hline Tahu & \multicolumn{2}{c}{ Tidak tahu } & & \\
\hline Tahu & 11 & 84,6 & 0 & 0,0 & 11 & 84,6 & 0,015 & 0,365 \\
Tidak tahu & 1 & 7,7 & 1 & 7,7 & 2 & 15,4 & & \\
\hline Jumlah & 12 & 92,3 & 1 & 7,7 & 13 & 100 & & \\
\hline
\end{tabular}

Sumber:Data primer 2019

Berdasarkan tabel 5.5 diatas menunjukkan hubungan pengetahuan ibu hamil primigravida trimester I dari 13 responden ada 11 responden $(84,6 \%)$ yang tahu tentang kehamilan dan dapat mendeteksi secara dini tanda bahaya dalam kehamilan, sebanyak 1 $(7,7 \%)$ yang tahu tentang kehamilan namun tidak tahu mendeteksi secara dini tanda bahaya pada kehamilan, sebanyak 1 responden $(7,7 \%)$ yang tidak tahu tentang kehamilan sekaligus tidak tahu mendeteksi secara dini tanda bahaya kehamilan.

b. Hubungan pengetahuan dengan deteksi dini tanda bahaya trimester II

Tabel 5.6

Hubungan pengetahuan dengan deteksi dini tanda bahaya trimester II di PMB Bidan "N" Kabupaten Gowa

\begin{tabular}{ccccccccc}
\hline Pengetahuan & \multicolumn{2}{c}{$\begin{array}{l}\text { Deteksi dini tanda bahaya } \\
\text { kehamilan trimester II }\end{array}$} & Jumlah & Nilai $\boldsymbol{p}$ & $\begin{array}{c}\text { Nilai } \\
\text { ph }(\boldsymbol{\mu})\end{array}$ \\
\hline & $\mathrm{N}$ & $\%$ & $\mathrm{~N}$ & $\%$ & $\mathrm{n}$ & $\%$ & & \\
\hline Tahu & 14 & 87,5 & 0 & 0,0 & 14 & 87,5 & 0,000 & 1,000 \\
Tidak tahu & 0 & 0,0 & 2 & 12,5 & 2 & 12,5 & & \\
\hline Jumlah & 14 & 87,5 & 2 & 12,5 & 16 & 100 & & \\
\hline
\end{tabular}

Sumber:Data primer 2019

Berdasarkan tabel 5.6 diatas menunjukkan hubungan pengetahuan ibu hamil primigravida trimester II dari 16 responden ada 14 responden $(87,5 \%)$ yang tahu tentang kehamilan dan dapat mendeteksi secara dini tanda bahaya pada kehamilan, sebanyak 2 responden $(12,5 \%)$ yang tidak tahu tentang kehamilan sekaligus tidak tahu mendeteksi secara dini tentang tanda bahaya kehamilan. 
Tabel 5.7

Hubungan pengetahuan dengan deteksi dini tanda bahaya trimester III di PMB Bidan "N" Kabupaten Gowa

\begin{tabular}{cccccccccc}
\hline Pengetahuan & \multicolumn{3}{c}{$\begin{array}{c}\text { Deteksi dini tanda bahaya } \\
\text { kehamilan trimester III }\end{array}$} & Jumlah & & Nilai $p$ & $\begin{array}{c}\text { Nilai } \\
\mathrm{ph}(\mu)\end{array}$ \\
\cline { 2 - 7 }$&{\mathrm{N}} &{\%} &{\mathrm{~N}} &{\%} &{\mathrm{n}} &{\%} &{ } &{ } \\
{\hline \text { Tahu }} &{18} &{85,7} &{0} &{0,0} &{18} &{85,7} &{0,012} &{0,548} \\
{\text { Tidak tahu }} &{2} &{9,5} &{1} &{4,8} &{3} &{14,3} &{ } &{ } \\
{\hline \text { Jumlah }} &{20} &{95,2} &{1} &{4,8} &{21} &{100} &{ } &{ } \\
{\hline}$
\end{tabular}

Sumber:Data primer 2019

Berdasarkan tabel 5.7 diatas menunjukkan hubungan pengetahuan ibu hamil primigravida trimester III dari 21 responden ada 18 responden $(85,7 \%)$ yang tahu tentang kehamilan dan dapat mendeteksi secara dini tanda bahaya kehamilan, sebanyak 2 responden $(9,5 \%)$ yang tidak tahu tentang kehamilan terdapat 1 responden $(4,8 \%)$ tidak tahu mendeteksi secara dini tanda bahaya kehamilan.

\section{PEMBAHASAN}

Pusat perhatian dalam penelitian ini adalah hubungan pengetahuan ibu hamil primigravida dengan deteksi dini tanda bahaya kehamilan yang di bedakan berdasarkan trimester.

1. Hubungan pengetahuan dengan deteksi dini tanda bahaya kehamilan trimester I

Hasil penelitian menunjukkan dari 50 responden terdapat 13 responden dengan umur kehamilan trimester I. Hubungan pengetahuan ibu hamil primigravida trimester I dari 13 responden ada 11 responden $(84,6 \%$ ) yang tahu tentang kehamilan dan dapat mendeteksi adanya tanda bahaya dalam kehamilan, sebanyak $1(7,4 \%)$ yang tahu tentang kehamilan terdapat namun tidak tahu mendeteksi adanya tanda bahaya pada kehamilan, sebanyak 1 responden $(7,7 \%)$ yang tidak tahu tentang kehamilan sekaligus tidak tahu mendeteksi adanya tentang tanda bahaya kehamilan.

Berdasarkan hasil analisis statistik uji chisquare sehingga diperoleh nilai $p=0,015$ lebih kecil dari nilai $a=0,05$, sehingga hasil penelitian antara dua variabel bermakna yaitu ada hubungan antara pengetahuan ibu hamil primigravida trimester I dengan deteksi dini tanda bayaya kehamilan.

Dari hasil diatas peneliti berasumsi bahwa ibu hamil primigravida khususnya ibu hamil trimester I yang tahu tentang kehamilan dapat pula dengan mudah mendeteksi adanya tanda bahaya pada kehamilannya agar dapat lebih cepat mengambil keputusan untuk mengunjungi fasilitas kesehatan. Factor lain yang dapat menyebabkan ibu hamil tidak mengetahui deteksi dini tanda bahaya pada kehamilan yaitu kurangnya informasi yang di dapatkan mengenai tanda bahaya, dalam hal ini penyuluhan tentang deteksi dini tanda bahaya kehamilan sangat menljadi hal yang harus di perhatikan agar dapat meningkatkan penegetahuan ibu hamil khususnya ibu hamil primigravida dalam melakukan deteksi dini tanda bahaya kehamilan.

Penelitian ini sejalan dengan hasil menurut hasil penelitian Fadilayana Damanik dkk pada tahun 2015 yang diperoleh dengan menggunakan uji Mc.Nemar di peroleh angka Significancy menunjukkan angka 0,532 . Nilai $p>0,05$, maka terjadi perbedaan pengetahuan tentang tanda bahaya kehamilan pada ibu hamil primigravida sebelum dan sesudah penyuluhan tidak signifikan.

2. Hubungan pengetahuan dengan deteksi dini tanda bahaya kehamilan trimester II

Hasil penelitian yang didaptkan yaitu dari 50 responden ada 16 responden dengan umur trimester II menunjukkan hubungan pengetahuan ibu hamil primigravida trimester II dari 16 responden ada 14 responden $(87,5 \%)$ yang tahu tentang kehamilan dan dapat mendeteksi secara dini tanda bahaya dalam kehamilan, sebanyak 2 responden (12,5\%) yang tidak tahu tentang kehamilan sekaligus tidak tahu mendeteksi secara dini tentang tanda bahaya kehamilan.

Berdasarkan hasil analisis statistik uji chi-square sehingga diperoleh nilai $p=0,000$ lebih kecil dari nilai $\alpha=0,05$, sehingga hasil penelitian antara dua variabel bermakna yaitu ada hubungan antara pengetahuan ibu hamil primigravida trimester II dengan deteksi dini tanda bayaya kehamilan.

Dalam hal ini peneliti berasumsi bahwa jika seorang ibu hamil trimester II mengetahui apa itu kehamilan khususnya pemeriksaan kehamilan dan dapat mendeteksi dini adanya tanda bahaya kehamilan maka ibu hamil 
tersebut dapat menjaga kehamilannya serta lebih dapat mengambil keputusan apabila terjada tanda bahaya pada kehamilannya. Hal ini juga dapat juga dapat berkaitan dengan informasi yang di dapatkan ibu hamil primigravida khususnya trimester II dari membaca buku KIA (kesehatan ibu dan anak) atau lebih di kenal dengan sebutan buku pink karena di dalamnya banyak informasi tentang cara mendeteksi dini adanya tanda bahaya pada kehamilan serta dapat pula di dapatkan melalui informasi dari petugs kesehatan dengan bertanya-tanya tentang tanda bahaya kehamilan saat melakukan kunjungan Antenatal care

$\mathrm{Hal}$ ini sesuai dengan penelitian

Lestari, Susetyo, Santosoyakni sebesar $79,59 \%$ ibu hamil membaca buku KIA (kesehatan ibudan anak) untuk mendapatkan informasi tentang tanda-tanda bahaya kehamilan, namun hanya $31,97 \%$ ibuhamil yang bisa menyebutkan tanda-tanda bahaya kehamilan, sehingga sebagian besar ibu hamil di BPM Ny."E" mempunyai pengetahuan di kategorikan cukup $(46,9 \%)$

3. Hubungan pengetahuan dengan deteksi dini tanda bahaya kehamilan trimester III

Hasil penelitian yang didapatkan yaitu dari 50 responden ada 21 responden dengan umur trimester III menunjukkan hubungan pengetahuan ibu hamil primigravida trimester III dari 21 responden ada 18 responden $(85,7 \%)$ yang tahu tentang kehamilan dan dapat mendeteksi secara dini tanda bahaya dalam kehamilan, sebanyak 2 responden $(9,5 \%)$ yang tidak tahu tentang kehamilan sekaligus tidak tahu mendeteksi secara dini tentang tanda bahaya kehamilan, dan terdapat 1 responden $(4,8 \%)$ tidak tahu mendeteksi secara dini tentang tanda bahaya kehamilan.

Berdasarkan hasil analisis statistik uji chisquare sehingga diperoleh nilai $p=0,012$ lebih kecil dari nilai $\alpha=0,05$, sehingga hasil penelitian antara dua variabel bermakna yaitu ada hubungan antara pengetahuan ibu hamil primigravida trimester III dengan deteksi dini tanda bayaya kehamilan.

Dalam hal ini peneliti berasumsi dari hasil telaah kuisioner di dapatkan responden yang rajin melakukan pemeriksaan kehamilan akan lebih bisa mengetahui deteksi dini tanda bahaya kehamilan, khususnya pada kehamilan trimester III harus lebih sering memperhatikan pemeriksaan kehamilan agar lebih bisa mempersiapkan diri menghadapi persalinan.
Penelitian ini sejalalan dengan hasil penelitian yang dilakukan oleh Fitriana pada tahun 2011 dengan hasil penelitiannya yaitu hubungan pengetahuan tentang tanda bahaya kehamilan dengan kepatuhan melakukan ANC di dapatkan 16 responden $(51,6 \%)$ Setelah data penelitian tersebut diolah, selanjutnya dilakukan pengujian data untuk menguji hubungan antara tingkat pengetahuan tentang tanda bahaya kehamilan dengan kepatuhan melakukan ANC dengan menggunakan Kolmogorov Smirnov. Hasil uji statistik didapatkan harga $Z$ hitung 1,552 dengan signifikan 0,016, $\rho$ value $<0,05$. Dengan demikian maka $\mathrm{Ho}$ ditolak dan $\mathrm{Ha}$ diterima. Jadi dapat disimpulkan bahwa ada hubungan yang signifikan antara tingkat pengetahuan tentang tanda bahaya kehamilan dengan kepatuhan melakukan ANC di BPS Sri Martuti Piyungan.

\section{KESIMPULAN}

Dari hasil penelitian 50 responden ibu hamil primigravida dengan 13 responden trimester I, 16 respondent trimester II dan 21 responden trimester III. Bahwa pengetahuan sangat berhubungan dengan deteksi dini tanda bahaya pada kehamilan, dari 50 responden yang terbagi berdasarkan trimester kehamilan di dapatkan bahwa apabila responden mengetahui kehamilan khususnya pentingnya pemeriksaan kehamilan maka dapat dengan mudah mendeteksi secara dini tanda bahaya kehamilan.

\section{SARAN}

Bagi PMB Bidan "N" kabupaten Gowa Diharapkan hasil penelitian ini dapat menjadi bahan pertimbangan dan evaluasi kepada pihak PMB agar dapat meningkatkan pemberian pendidikan kesehatan kepada pasien yang datang memeriksakan kehamilannya tentang pentingnya mengetahui deteksi dini tanda bahaya kehamilan

Bagi Tenaga Kesehatan Diharapkan dapat memberikan informasi (penyuluhan) yang lebih lengkap tentang deteksi dini tanda bahaya kehamilan dan memberikan pengetahuan tentang pentingnya memeriksakan kehamilan daan pemanfaatan buku KIA Bagi Peneliti Selanjutnya Diharapkan kepada peneliti selanjutnya untuk mengembangkan penelitian ini tetapi dengan metode atau variabel yang berbeda.

\section{UCAPAN TERIMA KASIH}

Penulis mengucakan terima kasih dan penghargaan kepada Jurusan Kebidanan, Politeknik Kesehatan Kemenkes RI Makassar, PMB Bidan N Kabupaten Gowa yang telah mengizinkan penelitian dengan hasil yang dapat digunakan untuk publikasi Bersama 


\section{DAFTAR PUSTAKA}

Prawirohardjo, Sarwono. 2014. IImu Kebidanan Sarwono Prawirohardjo. Jakarta: PT. Bina Pustaka Sarwono Prawirohardjo

World Health Organization. 2014. Levels and Trend Maternal Mortality Rate 2014. Geneva: WHO.

Notoatmodjo,S. 2012. Metodologi Penelitian Kesehatan. Jakarta: Rineka Cipta.

Notoatmodjo,S. 2015. Metode Penelitian Kesehatan, Jakarta: Rineka Cipta.

Agus, R. 2013. Kapita Selekta Kuesiner Pengetahuan dan Sikap dalam Penelitian Kesehatan. Jakarta: Salemba Medika.

Lestari, Titik. (2015). Kumpulan Teori untuk Kajian Pustaka Peneltirian Kesehatan. Yogyakarta : Nuha Medika.

Rustam, Mochtar. 2012. Sinopsis Obstetri: Obstetri Fisiologi, Obstetri Patologi. Jakarta: EGC.

Saifuddin. 2013. Metode Penelitian . Yogyakarta: Pustaka Pelajar.

Pelayanan Kesehatan Maternal dan Neonatal . Yayasan Bina Pustaka Sarwono Prawirohardjo. Jakarta.

Poedji Rochjati. Skrining antenatal pada ibu hamil. Surabaya: Airlangga

Ayurai. (2009). Aborsi dengan sikap remaja luntas. EGC. Jakarta.

Hendrayani, C.,2009. Hubungan Rasio Asupan Natrium:Kalium dengan Kejadian Hipertensi pada Wanita Usia 25-45 Tahun di Komplek Perhubungan Surabaya. Skripsi. Universitas Diponegoro, Semarang.

Poedji Rochjati. Skrining antenatal pada ibu hamil. Surabaya: Airlangga

Sulistyawati,Ari.2010.Buku Ajar Asuhan Kebidanan pada ibu hamil.Jakarta: Salemba Medika

Riwidikdo, H. 2012. Statistik Kesehatan. Yogyakarta: Nuha Madika.

Jonathan, Sarwono. 2006. Metode Penelitian Kuantitatif dan Kualitatif. Yogyakarta Graha IImu

Sugiyono. 2012. Metode Penelitian Kuantitatif Kualitatif dan R\&D. Bandung: Alfabeta.

Arikunto, S. (2013). Prosedur Penelitian: Suatu Pendekatan Praktik. Jakarta:Rineka Cipta. 